\title{
Proceeding
}

9th INSHS International Christmas Sport Scientific Conference, 4-6 December 2014. International Network of Sport and Health

Science. Szombathely, Hungary

\section{Teaching method of physical education and sports by prescriptive or heuristic learning}

\author{
GAETANO RAIOLA $\triangle$, DOMENICO TAFURI \\ University of Parthenope, Naples, Italy
}

\begin{abstract}
Raiola, G., \& Tafuri, D. (2015). Teaching method of physical education and sports by prescriptive or heuristic learning. J. Hum. Sport Exerc., 9(Proc1), pp.S377-S384. The didactics traditionally is imparted by the coach/trainer/teacher with tutorials that have the theoretical basis in the Cognitive approach. It means the coach/trainer/teacher illustrates in greater detail by the coach, are of Partial type, Varied, Randomized and Mental Training. It refers to the models of motor control to Open Loop, Closed Loop, and Motor Program Generalized. Teaching Methods of Physical activity is also imparted by another approach called Ecological-Dynamic where the coach does not require the tutorials, but builds a setting learning environment aimed at variety of learning. It refers to the models for the control of the Motor Imagery and Freedom Degrees. The first one could be in first person and in third person; the second one is three consecutive steps: Reduction, Exploration and Capitalization of the degrees of freedom. Aim is to study the issue of motor control theory and its relation to learning process and body knowledge. It carries out specific aspect of learning approach. Main results show two types of correspondence: 1) between cognitive approach and motor control closed loop, open loop and generalized motor program; furthermore, there is a significant correspondence among order, demand, sequence and timing on movement learning: 2) between ecological dynamic approach and motor control Motor Imagery and Freedom Degrees; furthermore, there is a significant correspondence among setting, learning environment and specific strategies of teaching method such as cooperative learning, role playing, circle time, brain storming, peer education, tutorship, focus group. In this way it can see the invasive role of the coach/trainer/teacher in cognitive approach and non-invasive role in ecological dynamic approach. Key words: COGNITIVE, ECOLOGICAL-DYNAMIC, MOTOR CONTROL, SKILLS.
\end{abstract}

\footnotetext{
Corresponding author. University of Parthenope, Chia, Via Berenice 11, Napoli, Italy

E-mail: raiolagaetano@libero.it

9th INSHS International Christmas Sport Scientific Conference, 4-6 December 2014. International Network of Sport and

Health Science. Szombathely, Hungary.

JOURNAL OF HUMAN SPORT \& EXERCISE ISSN 1988-5202

(c) Faculty of Education. University of Alicante

doi:10.14198/jhse.2015.10.Proc1.28
} 


\section{INTRODUCTION}

Teaching method of physical activities and sport use traditionally tutorials and prescriptive exercise that have the theoretical basis in cognitive approach. The coaches, trainers and teachers play physical activities and sport throughout simulations, order, command that have the theoretical basis in Behaviourism theory and Cognitive one. They are, in greater detail, tutorial of Partial type, Varied one, Randomized one and, finally, Mental Training.

Refer to the models of motor control to Open Loop, Closed Loop, and Motor Program Generalized The partial tutorial consists in making exercise a motor skill complex initially in a simplified form. Movements with a certain degree of difficulty, very complex, can be simplified by dividing the exercises or reducing the speed or requests for precision. For all forms of partial tutorial is the rule that is obtained of learning only as long as the techniques of partial tutorial, that is fragmentation, segmentation and simplification, does not adversely affect the deep structure of the motor program generalized. The tutorial randomized and that varied are other techniques of tutorial that find their justification in theory engine programs generalized. The theory of the programs motors has generalized methodological implications-didactic on direct choice of which provide information in the feedback. This choice depends on the type of error made by the athlete/student. The techniques of mental repetition consist in think about the aspects cognitive and procedural of the action, while the mental representation is to imagine the conduct of an action. In the teaching of physical activities and sport there is also another approach, it titles Ecological-Dynamic where the coach does not require the tutorials but builds a setting learning environment aimed at variety of learning (Raiola et al., 2013abc). It refers to the models for the control of the imagination and mobility of the theory of the degrees of freedom in three consecutive steps for learning impairment: Reduction, Exploration and Capitalisation of the degrees of freedom. According to the ecological approach "learn" means being able to find progressively the mobility solution best for a given task in a given context.

Emblematic is the expression, coined by Bernstein (1935) "repetition. without repetition": practice does not mean always repeat the same solution to a given task, but repeat over again the process of solving the task itself. If learn movements means optimizing the process of solving tasks engines, resulting didactic implications different from those prescriptive learning own cognitive approach. In heuristic learning, the teacher has to assist the student in research autonomous mobility solutions and he does not give indications, solutions, order or command. If the learning tasks too complex, you should not impose constraints to the learner in telling him how prescriptive simplify the implementation mobility, but he has to apply constraints at the environment. Basketball, as well as other sports game, is an example where periodization and quantitative aspects are founded in an unique phenomenon to planning the training. (Ammar et al., 2015; Attene et al., 2015). Aim is to study the issue of body knowledge (Rio et al., 2014) by motor control theory and its relation to skills. Furthermore, to aim if there is a several mode to teach, to train, to coach and how the student/athlete learns and which is the setting or the learning environment

\section{METHODS}

To work by elaboration of specific aspects on motor control and learnings of physical activities and sport. It uses an integrated method that joins, in one hand, a historical and documentary way to describe the evolution steps, particularly on theoretical paradigms on teaching method and its didactics. In other hand, it uses an argumentative, interpretative and deductive approach to talk about on the better choice to favour the sports skill and learnings. 


\section{RESULTS}

The current state of the affair of how and why the body and movement are central in skills, through methodological and didactic choices in teaching activities at whose foundation there is scientific evidence.

Firstly, it is synthesized in Cognitive approach and Ecological-Dynamic one. Humans have, in the brain, a series of motor programs, or sequences of commands that, in the central nervous system, coordinate the execution of movements. According to this scientific idea, processing of information from sense organs allows the system to correct the movement at timing execution. The closed-loop motor control theory (Adams, 1968) assumes that the movements are sufficiently slow to allow correction during implementation, based on the data from the feedback and its utilization to correct the movement. This is sufficiently slow when every information on movement, scientific called feedback, could be processed by mind in two hundreds milliseconds and so it is used by the effectors, muscles, nerve cell, articulation, bode, ligament and tendons. The longer the execution time, the wider the opportunity to use the motor control circuits based on feedback and comparison between memory trace and perceptual trace. Memory trace is the ideal motor program to take place and effect as well as is in the mind without errors while Perceptual trace is the real motor program that is effected with the errors (Adams, 1975). Comparison is the process which the mind to determine the differences between to ideal motor program and real one to carry out the errors by the feedbacks. In other word, when motion is quicker than of nerve impulses conduction (up two milliseconds), the movement is not susceptible of correction in progress and is programmed completely in the central nervous system due to the inability of the brain to process information and data below the time threshold of two hundred milliseconds according to open loop motor control theory (Schmidt, 1985; Keele et al., 1986). Open loop and closed loop are two of the most important theory of motor control and learning, nowadays it must includes a new theory that can better explain the motor learning (Di Tore \& Raiola, 2012).

Learning movement consists of developing cognitive structures, known as motor program, through information processing. These processes allow the opportunity to compare in real time, by closed-loop motor control, or later, by open-loop motor control theory, obtain results, triggering a process of adjustment and refinement of movement. Its structure is such that allows the performer to adjust the movement in order to meet the changing needs of the environment. In this way, the generalized motor program (Schimdt \& Wrisberg 2004) joins the feedback and comparator between memory trace and perceptual trace, as occurs in closed-loop, and the innate properties of motor centralized program and the exceeding the limit of time threshold of two hundreds of milliseconds to elaborate, the perception, as occurs in open-loop. All of these three motor control theory, open-loop, closed-loop and generalized motor program, are the basis of the cognitive approach.

Cognitive approach is used by prescriptive style teaching and has its basis on the preeminent role of the voluntary and determined movement on the environment. Thus, it can talk the prescriptive learnings in physical activity and sport, which means the teacher/trainer/coach guides the whole process. He gives the order, command, timing, sequence, aim, goal, monitoring and the reprogram the activities (fig. 1,2,3). Synthetically, prescriptive learnings follows the cognitive approach in mental activity and give the great role at the teacher/trainer/coach. In this way, the educational setting has a minority importance than the other approach, called ecological dynamic one, because of the invasive teacher role in prescriptive way. The direct consequence of the cognitive theory in educational applications is a prescriptive approach, with a teacher who directs the structure of motor programs, with increasing complexity, and the optimization of their parameters. The aim of the exercises will be to stabilize and improve motor program by reducing the variability in execution through the repetition method and other didactics such as exercise varied, 
segmented, randomized and idea motion training. Finally, in cognitive approach, skill learning means to stabilize an efficient motor program according to special processing information.

Cognitive approach is not sufficient to explain every aspects of motor control and learning and several scientists have been investigated in other way. Below is presented a brief summary of the main currents of thinking in the context of motor control and learning, in order to evaluate the resulting of teaching methods, and so to verify if the indications presented in the educational documents can be traced back to such theories. First of all, it is used to know the embodied cognition has the basis of neurological aspects. "Conceptual knowledge is embodied, that is mapped in our sensory-motor system. This not just provides the structure to the conceptual content, but characterizes the semantic content of concepts according to the way we function in the world with our bodies." (Gallese \& Lakoff, 2005). So, it can elaborate another approach to physical activity and sport.

The ecological approach, opposite approach of to cognitive one, does not consider necessary to use prescribing mental structures: the action is directly available to those who act in their own environment, the self-organization that do not require the use of a motor program (Edelman, 1987). In this approach, learning is defined as an education of attention (Gibson, 1986). Learning means to optimize the processes of perception and develops the ability to dictate the specific stimulus (Altavilla et al., 2014; Raiola, 2014; Raiola et al., 2014; Gaetano et al,, 2014; Napolitano et al., 2013abc). In this vision, the perception of the context is different and, so, the learning process is defined differently. In ecological-dynamic approach, skill learning is to seek the adaptability of the movement as resulting by the diversity of the environment and the specificity of the individual (Carnus \& Marsualt, 2003).This approach considers human behaviour in evolution because of a complex systems, where the complex system is a set, the whole phenomenon, the specific environment where the human being moves and make several interactions, subsequently of multiple interacting factors made by body segments. In the dynamic perspective learning is to build and stabilize a new state not included in the initial coordination dynamics of the system. Teaching methods, in ecological-dynamic approach, is designed to stimulate the emergence of spontaneous solutions, called heuristics to motor problems, taking advantage of variability in executive search process that implements a mobility solution that passes through the continuous variation of motor gestures. Syntactically, it is called heuristic learning because of the direct dependence at unique relationship with the problem. The phenomenon and its relation, inside of it, can determine every solution that cannot predetermine before the action, but it has to start and then should be predetermine (fig $3,4,5$ ). In this way the educational setting is the main aspects to facilitate the skills. Mainly, the basis of this approach is the freedom degrees theory or Bernstein's problem by Nikolay Alexdrovic Bernstein (1967) that introduces, for the first time, the interaction of single movement in the holistic vision. His research showed that most movements, like hitting a chisel with a hammer, are composed of smaller movements by three steps to learn the movement. Any one of these smaller movements, if altered, affect the movement as a whole. The three steps are: reductions freedom degrees, exploration freedom degrees and capitalization freedom degrees.

The first one consists to immobilize one or plus articulations to execute by repetitions the same action, the second one occurs when in consequence to immobilize one articulation to explore other movements to aim the same outcomes or to give freedom some of articulations that before are immobilized. The last one is when it organizes the whole movement with the feedbacks by reduction freedom and exploration degrees to perform the movement by repetitions which are differently among them because one movement is different to others. For this reason, Bernstein called this phenomenon "repetition without repetitions" (Bernstein, 1991). Later, this motor control system has been considered as motor imagery (Lotze \& Halsband, 2006). The knowledge of structural and functional organization of the motor system has evolved 
and deepened in recent years, gradually abandoning the idea of a brain where the processing of sensory information was entrusted to different and dedicated cortical areas, according to a model in which sensory and motor information are very interdependent (Latash, 2004). A central role in this reversal of perspectives is due to the discovery of mirror neurons, early in monkeys and later in humans. It is motor imagery theory. Before to talk about it, it has to introduce some new neurological discoveries: Mirror neurons system. "Mirror neurons are for neuroscience what the DNA was for biology" (Vilayanur Ramachandran, in lacoboni, 2008). Studies in human brain have shown the existence of mirror neurons system similar to that discovered in monkeys while the "Group of Parma of Giacomo Rizzolatti" (1996) has noted that they responded both when the monkey performed directly the movement of reaching the food, either when was another individual to perform the action by recording the activity of certain neurons of motor area called F5 in grasping tasks in the brain of a monkey, a group of researchers (Rizzolatti et al., 2001). "Whenever we see someone performing an action, in addition to activation of the visual areas, there is a concurrent activation of motor cortical circuits that are normally active during the execution of these actions. In other words, the observation of an action involves the simulation of the same. The fact that the motor system is active not only during the run, but also during observation of actions, suggests that exists a relationship between control and action representation "(Gallese et al., 1996). The discovery of a same group of neurons involved in both perception and action dismisses the idea of specialized brain areas and implies interdependence between perception, cognition and motor system and motor learning produces parallel dynamic functional changes during the execution and imagination of sequential foot movement (Lafleur \& Jackson, 2002).

The first phase of motor learning is characterized by imperfect movements, a high dependence on feedback and a large cognitive and attention load (Atkeson, 1989). The evolution and stabilization of learned movements is reflected in neuroanatomical level, on a change in brain areas recruited and activated neuronal circuits (Halsband \& Lange, 2006). While the immediate repetition of an observed action is supported almost exclusively by the mirror neuron system, learning by imitation requires the intervention of the prefrontal lobe, particularly in the area 46 of Brodmann, and some areas of the cortex anterior mesial. The area 46 , generally associated with functions related to working memory, in this case plays a role in combining elementary motor acts in more complex motor patterns. During the learning process, in fact, mirror neurons are responsible for the allocation of the observed action into individual pieces, which are then reassembled into a sequence so that appropriate action is reproduced as close as possible to that observed (Zwicker et al., 2011). The motor imagery (MI) is a cognitive process of mental simulation of an action in the absence of physical movement. MI was deeply investigated also by Marc Jeannerod. One of the most scientist about the neurological process. He had lived between 1935 and 2011, its scientific life was entirely dedicated at neurology and neurophysiology, as well as other Scientifics about cognitive neuroscience and experimental psychology are interested. Specially, the mechanisms underpinning motor control, motor cognition are investigated by Decety in 1996, Driskell and Copper in 1994, Gallese and Rizzolatti between 1996-2012, Lafleur in 2002, Sanders in 2004. It also defined as a state of general activation during which a person feels himself to perform an action.

The motor imagery should be distinguished from mental practice, the first refers to the cognitive process while, the second refers to the process of mental training that takes advantage of the first process. There are two types of motor imagery: in first-person and in third-person. In first person mode, the subject imagines himself to perform an action but not in the sense of seeing himself as an external or reflected image, in the sense to see what he would see, if he performed a movement and at the same time feel emotions, excitation, stress and changes of arousal. In third person mode, the person sees himself or another person as an external image, as with the use of a camera. The most effective for learning is that 
first-person. Numerous studies have shown that the performance is optimized through the cognitive process of motor imagery. During the motor imagery the cerebral areas of the pre-motor cortex, the same which a muscular contraction would put in action, are activated. The ability to create an inter-subjective space which is then shared with the world is connected to the role played by embodied simulation, neuroscientifically based on mirror neurons.

Thus, the ecological dynamic approach is based by two of the main motor control theories: Freedom Degrees and Motor Imagery. The learnings have the heuristic processes and togetherness at educational setting make outcomes in order to the followings psychological techniques: cooperative learnings, role play, circle time, brain storming, focus group, peer education, tutorship.

\section{CONCLUSIONS}

Teaching method of Physical education in school has to be considered according to the ministerial documents (Raiola, 2011ab; Raiola, 2012ab; Gaetano, 2012ab). In this way, the knowledge is quickly developing and the changed are too fast to include in revision. It is useful to involve scholars in applied study in educational field of school and of sports club to have the same scientific idea. Too often, the world of school and the sports one are too away each other to collaborate. Cognitive approach is an usual way to understand the movement, that is the historical way to study and investigate the issue in behaviourist / cognitive interpretative key. Ecological Dynamic approach is an extraordinary way to understand the movement that is the innovation way to study and investigate the issue in gestalt/phenomenology interpretative key.

\section{REFERENCES}

1. Adams, J.A. (1971). A closed-loop theory of motor learning. Journal of Motor. Behavior, 3, pp.111115.

2. Adams, J.A. (1968). Response feedback and learning. "Psychological Bulletin", 70, 486-504. teaching relevance and availability of Anochin's theoretical model. Sport Science, 4(2).

3. Altavilla, G., Tafuri, D., \& Raiola, G. (2014). Some aspects on teaching and learning by physical activity. Sport Science, 7(1), pp.7-9.

4. Altavilla, G., \& Raiola G. (2015). Sports Game Tactic in Basketball. Sport Science, 8(1).

5. Astin, J.A., Shapiro, S. L., Eisenberg, D.M., \& Forys, K.L. (2003). Mind-body medicine: State of the science, implications for practice. Journal of the American Board of Family Practice, 16, pp.131147.

6. Atkeson, C.G. (1989). Learning arm kinematics and dynamics. Annu. Rev. Neurosci, 3, pp.171176.

7. Bernstein, N.A. (1967). The co-ordination and regulation of movements. Oxford : Pergamon Press

8. Bernstein, N.A. (1991). On co-ordination and its development. Moskow: University press

9. Buchta, K. (2011). The Course and Didactic Results of Master's Studies in Physical education. Polish Journal of Sport and Tourism, 18(1), pp.69-74.

10. Carnus, S., \& Marsualt, C. (2003). Repenser l'EPS à partir de l'approche ecologique. Rivista EPS, édition revue EPS, 302, pp.13.

11. Curry, L.A., \& Maniar, S.D. (2003). Academic course combining psychological skills training and life skills education for university students and student-athletes. Journal of Applied Sport Psychology, 15, pp.270-277. 
12. Curry, L.A., \& Maniar, S.D. (2004). Academic course for enhancing student-athlete performance in sport. The sport Psychologist, 18, pp.297- 316.

13. Di Tore, P.A., \& Raiola, G. (2012). Exergames in motor skill learning. Journal of Physical Education and Sport, 12(3), pp.358-361.

14. Edelman, G.M. (1987) Neural Darwinism. The theory of Neuronal group Selection. Basic Books: New York.

15. Gaetano R., Domenico T., \& Gaetano A. (2015). Physical activity and its relation to body and ludic expression in childhood. Mediterranean Journal of Social Sciences, 6(3).

16. Gaetano R., Gomez F.P., \& Gaetano A. (2015). Anxiety In The Youth Physical And Sport Activity. Mediterranean Journal of Social Sciences, 6(3).

17. Gaetano, R. (2012a). Motor learning and didactics into physical education and sport documents in middle school-first cycle of education in Italy. Journal of Physical Education and Sport, 12(2), pp.157-163.

18. Gaetano, R. (2012b). Didactics of volleyball into the educate program for coaches/trainers/technicians of Italian Federation of Volleyball (FIPAV). Journal of Physical Education and Sport, 12(2), pp.25-29.

19. Gaetano, R., Rago, V. (2014). Preliminary study on effects of hiit-high intensity intermittent training in youth soccer players. Journal of Physical Education and Sport, 14(2), pp.148-150.

20. Gallese V., Fadiga L., Fogassi, L., \& Rizzolatti G. (1996). Action recognition in the premotor cortex. Brain, 119, pp.593-609.

21. Gallese, V., \& Lakoff, G. (2005). The Brain's concepts: the role of the Sensory-motor system in conceptual knowledge. Cognitive Neuropsychology, 22(3/4), pp.455.

22. Gibson, J.J. (1979) The Ecological Approach to Visual Perception. Boston: Houghton Mifflin

23. Jeannerod, M. (2006). Motor cognition: What actions tell the Self. Oxford: University Press

24. Jeannerod, M. (2002a). Le Cerveau intime. Paris: Editions Odile Jacob.

25. Jeannerod, M. (2002b). La Nature de l'esprit. Paris: Editions Odile Jacob.

26. Hagman (eds.), Transfer of learning (pp. 47-79). Orlando, FL: Academic Press.

27. Halsband, U., \& Lange, R. K. (2006) Motor learning in man: A review of functional and clinical studies. Journal of Physiology - Paris, 99, pp.414-424.

28. Hutchins, E. (1995). Cognitions in the wild. Cambridge, MA: MIT Press.

29. lacoboni, M. (2008). I neuroni specchio. Come capiamo ciò che fanno gli altri. Bollati Boringhieri

30. Kelee, R.L. (1984). Micro-Determinism and Concepts of Emergence. Philosophy of Science, 51(1), pp.44-63.

31. Lafleur, M. \& Jackson, P. (2002). Motor learning produces parallel dynamic functional changes during the execution and imagination of sequential foot movement. Neuroimage, 16, pp.142-157.

32. Latash, M.L. (2004). Progress in Motor Control: Bernstein's Traditions in Movement Studies, Vol. 1 USA: Human Kinetics.

33. Lotze, M., \& Halsband, U. (2006) Motor imagery. Journal of Physiology-Paris, 99(4-6), pp.386-395.

34. Napolitano, S., Di Tore, P.A., \& Raiola, G. (2013a). High diving: Evaluation of water impact and considerations on training methods. Journal of Human Sport and Exercise, 8(2), pp.290-296.

35. Napolitano, S., Tursi, D., Di Tore, P.A., \& Raiola, G. (2013b). Tactics -based on waterpolo training. Journal of Human Sport and Exercise, 8(2), pp.271-282.

36. Napolitano, S., Tursi, D., Raiola, G. (2013c). Waterpolo women's pattern tactical experience of an Italian team. Journal of Human Sport and Exercise, 8(3), pp.660-670.

37. Pethkar, V., Shraddha Naik, S., \& Sonawane, S. (2010). Attitudes toward physical activity and its measurement. Journal of Physical Education and Sport, 29(4), pp.30-36. 
38. Polidoro. L., Bianchi, F., Di Tore, P.A., \& Raiola, G. (2013). Futsal training by video analisis. Journal of Human Sport and Exercise, 8(2), pp.290-296.

39. Raiola, G. (2015). Inclusion in sport dance and self perception. Sport Science, 8(1).

40. Raiola, G., \& Tafuri, D. (2015). Assestment and periodization in amateur soccer team. Sport science, 8(2).

41. Raiola, G., Tafuri, D., \& Paloma, G. (2014). Physical activity and sport skills and its relation to mind theory on motor control. Sport Science, 7(1), pp.52-56.

42. Raiola, G. (2011a). Study between neurophysiological aspects and regulation documents on preschool in Italy. Journal of Physical Education and Sport, 11, pp.42-47.

43. Raiola, G. (2011b). A study on Italian primary school rules: Neurophysiological and didactics aspects in physical education and sport. Journal of Physical Education and Sport, 11(2), pp.43-48.

44. Raiola, G. (2012a). Motor learning and didactics into physical education and sport documents in middle school-first cycle of education in Italy. Journal of Physical Education and Sport, 12(2), pp.157-163.

45. Raiola, G. (2012b). Bodily Communication in Volleyball Between Human and Experimental Sciences. Mediterranean Journal of Social Sciences, 3, pp.587-597. http://dx.doi.org/10.5901/mjss.2012.03.01.603

46. Raiola, G., Scassillo, I., Parisi, F., \& Di Tore, P.A (2013a). Motor imagery as a tool to enhance the didactics in physical education and artistic gymnastic. Journal of Human Sport and Exercise, 8(2), pp.93-97.

47. Raiola, G., Giugno, Y., Scassillo, I., \& Di Tore, P.A. (2013b). An experimental study on Aerobic Gymnastic: Performance analysis as an effective evaluation for technique and teaching of motor gestures. Journal of Human Sport and Exercise, 8(2), pp.297-306.

48. Raiola, G., Parisi, F., Giugno, Y., \& Di Tore, P.A. (2013c). Video analysis applied to volleyball didactics to improve sport skills. Journal of Human Sport and Exercise, 8(2), pp.307-313.

49. Raiola, G. (2014). Motor control and learning skills according to cognitive and ecological dynamic approach in a vision on behaviorism, cognitive, Gestalt and phenomenology theories. Mediterranean Journal of Social Sciences, 5(15), pp.504-506.

50. Raiola, G., Tafuri, D., \& Paloma, G. (2014). Physical activity and sport skills and its relation to mind theory on motor control. Sport Science, 7(1), pp.52-56.

51. Rio, L., Di Rubbo, N., \& Gomez Paloma, F. (2014). Natural acquisition of the second language through routine movements in children. Journal of Human Sport and Exercise, 9(1), pp.355-358.

52. Rizzolatti, G., Fadiga, L., Gallese, V., \& Fogassi, L. (1996). Premotor cortex and the recognition of motor actions. Cogn. Brain Res., 3, pp.131-141.

53. Rizzolatti, G. (2006). So quel che fai. Il cervello che agisce e i neuroni specchio. Milano: Raffaello Cortina Editore.

54. Schimdt, R., \& Wrisberg, D. (2004). Motor Learning and Performance. USA: Human Kinetics.

55. Tursi, D., Napolitano, S., Di Tore, P.A., \& Raiola, G. (2013a). Arm stroke: A comparative analysis between competitive swimming and water polo athletes. Journal of Human Sport and Exercise, 8(2), pp.313-321. 